potassium depletion. In this case fludrocortisone therapy caused intracellular potassium depletion, the compensatory influx of hydrogen ions leading to intracellular acidosis with consequent renal tubular hydrogen ion excretion and thus metabolic alkalosis. No sedation had been given to account for hypoventilation, which was considered compensatory.

This case demonstrates a less commonly documented cause of metabolic alkalosis and serves to demonstrate the consequences of poorly monitored fludrocortisone therapy, which fortunately responded to conservative management with potassium and potassiumsparing diuretics.

A BuRns TOM BROWN

Chest Unit,

Inverclyde Royal Hospital,

Greenock PA16 0XN

SIR,--It was interesting to read the paper by Drs Shahrokh Javaheri and Edward A Nardell about the extreme alkalosis in a hypertensive patient taking hydrochlorothiazide who also had a peptic ulcer. Though he was vomiting on admission it is difficult to accept this as the main cause of the alkalosis, as vomiting severe enough to cause this degree of metabolic derangement would ordinarily be expected to cause dehydration of greater biochemical significance than he had. As the history was also very short, it is more difficult to explain the normal blood urea, which in this cause could not have been due to chronic malnutrition. Aberrant reactions with excessive loss of sodium or potassium, or both, is a well-known complication of thiazide therapy and I wonder whether this, with its resultant total body depletion of potassium, explains the primary lesion in this patient. There was no history of use of liquorice extracts for his abdominal problems, so this is probably irrelevant here.

J K IKWUEKE

Southend Hospital,

Westcliff-on-Sea, Essex

SIR,-I was interested in the article by Drs Shahrokh Javaheri and Edward Nardell on "Severe metabolic alkalosis" (17 October, p 1016) associated with vomiting from pyloric stenosis complicating a peptic ulcer. These authors might be interested to know that I reported a case of pyloric obstruction leading to alkalosis, tetany, and coma. ${ }^{1}$ As the patient had been unconscious and anuric for over 24 hours and was a mere skeleton from emaciation I operated on him (in May 1942) without an anaesthetic or premedication. A gastroenterostomy was performed, followed by complete recovery.

GORDON UNGLEY

London SW3 4 TQ

${ }^{1}$ Ungley HG. Lancet 1948;ii 218.

SIR,-A recent paper by Drs $S$ Javaheri and E A Nardell (17 October, p 1016) describes the case of a man with severe metabolic alkalosis and hypokalaemia and concludes with the statement that the rapid recovery of this patient "underscores the importance of conservative treatment (volume expansion, potassium, and oxygen) even in the most severe cases of metabolic alkalosis."

This prescription omits the one essential requirement for correction of metabolic alkalosis in most cases-namely, the administration of chloride. The authors should be directed to the work of Kassirer and others ${ }^{1-3}$ on this subject. "Studies of hypokalaemic alkalosis in man have demonstrated that the provision of chloride is a prerequisite to restoration of normal acid-base and potassium equilibrium."1

Fortunately for their patient, the "volume expander" used by Drs Javaheri and Nardell was sodium chloride solution. Other volume expanders, and some potassium salts, are available that contain no chloride ion. The use of such preparations would correct neither the metabolic alkalosis nor the hypokalaemia.

Bethesda Hospital,

Cincinnati, Ohio 45206,

1 Kassirer JP, Berkman PM, Lawrenz DR, Schwartz WB. Amer $\mathcal{F}$ Med 1965;38:172-89.

Kassirer JP, Schwartz WB. Amer f Med 1966;40: $19-26$

Penman RW, Luke RG, Jarboe TM. f Appl Physiol $1972 ; 33(2): 170-4$.

\section{Colovesical fistula diagnosed by unconventional procedure}

SIR, - We wish to report a further example of a patient with a colovesical fistula diagnosed after identifying barium in the urine (see the report by Dr C O Bach and others, 31 October, p 1154).

An 87-year-old male presented with a threeweek history of anorexia, dysuria, and lower abdominal pain. Physical examination revealed tenderness in the left iliac fossa and in the suprapubic region but no abnormal mass was felt. Blood tests established an iron-deficiency anaemia and a high blood urea concentration. A midstream specimen of urine contained a large number of bacteria (Escherichia coli). An intravenous pyelogram was carried out and found to be normal. Cystoscopy revealed an area of inflammation on the left side of the posterior wall of the bladder. Biopsy of this area, however, showed no evidence of malignancy. Shortly after admission the patient had to be catheterised because of difficulty with micturition. A barium-enema examination failed to show any obvious abnormality. Within hours of completion of the investigation, however, barium appeared in the urine as a thick sediment and coated the container. These findings persisted for five days. At operation a large carcinoma of the sigmoid colon, adherent to and invading the bladder, was found and resected.

We would thus support the suggestion that patients with a suspected colovesical fistula should have their urine collected and examined for barium following a negative bariumenema investigation. Very small volumes of barium ( $1 \mathrm{ml}$ in 1 litre of urine) will produce a sediment and coat containers.

J Michael Dixon ROBERT R JEFFREY R SMITH O EREMIN

University Department of Clinical Surgery,

Royal Infirmary Edinburgh EH3 9YW

\section{Oesophageal perforation of fibreoptic gastroscopy}

SIR,-The Endoscopy Committee of the British Society of Gastroenterology has been following the letters in your columns by $\mathrm{Mr}$
K S Mullard, who has again repeated his assertion "that any patient suffering mishap at oesophagoscopy without preliminary radiology will have an almost irresistible claim for damages" (10 October, p 987). Mr Mullard based his view on extensive experience with the rigid oesophagoscope, which has become virtually obsolete for diagnostic purposes since he retired. Diagnostic oesophagoscopy, often carried out as part of an examination of the upper gastrointestinal tract, is now almost invariably done with the much safer flexible fibreoptic instrument. No evidence has been produced to support the claim that prior radiology will reduce the complication rate from fibreoptic endoscopy.

In view of the legal implications of $\mathrm{Mr}$ Mullard's statement the committee wishes to record its unanimous view that prior radiology is not an essential prerequisite for fibreoptic endoscopy. We regard radiology and endoscopy as being complementary. Patients with suspected oesophageal disease and especially dysphagia often require both investigations. This has been our practice for several years. Indeed, in 1976, when we carried out a survey of the membership of the former British Society for Digestive Endoscopy, only $12 \%$ of 172 endoscopy units insisted on prior radiology.

We share Mr Mullard's aim of reducing the complication rate for all endoscopic procedures and attempt to do so by fostering training, teaching materials, and scientific discussion.

\section{G COLIN-JONES} Vice-presiden

B STERry ASHBY Honorary secretary On behalf of the Endoscopy Committee, British Society of

Queen Alexandra Hospital, Cosham, Portsmouth

Prostaglandins $I_{2}$ and $E_{1}$ and red cell deformability in Raynaud's phenomenon and systemic sclerosis

SIR,-Dr Pauline $M$ Dowd and others (1 August, p 350) reported the effects of prostaglandin (PG) $E_{1}$ and $I_{2}$ infusion on red cell deformability. PGI is unstable in aqueous solution, being hydrolysed non-enzymically. The half life at $37^{\circ} \mathrm{C}$ and at a pH of 7.5 is three minutes. ${ }^{1}$ With a saline temperature of $25 \mathrm{C}$, the PGI concentration will be negligible after one hour. Since the PGI solution used was infused for 72 hours, even if the solution was freshly prepared there would be no activity present throughout most of the infusion period.

More than $95 \%$ of PGE administered by intravenous infusion is removed on the first passage through the pulmonary vascular bed." PGE is rapidly cleared from the blood, only $3 \%$ remaining after 90 seconds. ${ }^{3}$ If we assume first-order kinetics, the administration of 12 $\mathrm{ng} / \mathrm{kg} / \mathrm{min}$ will result in elevation of blood PGE concentrations by less than $0.01 \mathrm{nmol}$.

Eklund and Carlson, ${ }^{4}$ using intravenous $\mathrm{PGE}_{1}$ infusion rates of 10,50 , and $100 \mathrm{ng} / \mathrm{kg} /$ min, showed increased forearm blood in man only at the highest rate of infusion. The use of intravenous PGE to induce labour requires infusion at the rate of $1-8 \mu \mathrm{g} / \mathrm{min},{ }^{5}$ a rate much greater than that used in this study. Studies on isolated human dermal arterioles in vitro show that PGE causes vasoconstriction. ${ }^{6}$ PGE in high doses causes hyperthermia in man. ${ }^{5}$ Prostaglandin-induced fever is accompanied by reduced cutaneous flow in rhesus monkeys, ${ }^{7}$ cats, rats, rabbits, sheep, and squirrel monkeys. 
The available evidence does not show that PGE is an effective cutaneous vasodilator even when given at a rate sufficient to produce changes in blood flow. Its usefulness in Raynaud's disease ${ }^{\sharp}$ must therefore remain questionable.

The demonstration of changes in erythrocyte deformability following the infusion of inactive $\mathrm{PGI}_{2}$ solutions and after the administration of $\mathrm{PGE}_{1}$ at a rate insufficient to cause marked changes in haemodynamic values is therefore probably artefactual.

Department of Dermatology,

The Royal Free Hospital,

${ }^{1}$ Moncada S, Flower RJ, Vane JR. In: Gilman AG Goodman LS, Gilman A, eds. Pharmacological basis of therapeutics. 6th ed. New York: Macmillan,
$1980: 668-81$.

Ferreira SH, Vane JR. Nature 1967;216:868-73.

Hamberg M, Samuelsson B. I Biol Chem 1971;246: 6713-21.

Eklund B, Carlson LA. Prostaglandins 1980;20 333-47.

Gruber WS, Baumgarten K. Am $\mathcal{f}$ Obstet Gynecol $1980 ; 137: 8-14$

Goldyne ME, Winkelmann RK. F Invest Dermato $1973 ; 60: 258-62$.

Barney CC, Elizondo RS. I Appl Physiol 1978;44 Martin M, Dowd P, Ring F, Dieppe P, Kirby J.

* *We sent this letter to Dr Dowd, who replies below on behalf of her co-authors.-ED, $B M \mathcal{H}$.

SIR,-Mr Gaylarde is quite correct with regard to the instability of prostacyclin $\left(\mathrm{PGI}_{2}\right)$ in neutral solution. However, prostacyclin is stabilised by alkaline $\mathrm{pH}$ or decreased temperature. ${ }^{12}$ In the infusion solutions we employed, freeze-dried prostacyclin was reconstituted in saline buffered to $\mathrm{pH} 10.5$ with glycine (Glycine buffer, Wellcome Foundation Ltd) in which solution at ambient temperature it retains $90 \%$ of initial potency for at least 12 hours (personal communication by $\mathrm{Dr} J$ O'Grady) and has a half life of 100 hours. $^{2}$ The infusion solutions were freshly prepared and renewed at appropriate intervals to ensure that maximum activity was present in the buffered infusate throughout the infusion period.

In view of the fact that more than $95 \%$ of $\mathrm{PGE}_{1}$ is metabolised on first passage through the pulmonary vascular bed plasma, renin release from the kidney was estimated prior to and repeatedly during the infusion period with $\mathrm{PGE}_{1}$ and the control infusions of saline. Infusion of $\mathrm{PGE}_{1}$ alone produced greatly elevated levels of plasma renin (unpublished data), which indicates that a quantity of PGE adequate to produce pharmacodynamic effects entered the systemic circulation when $\mathrm{PGE}_{1}$ was administered by centrally placed intra venous catheters. Eklund and Carlson estimated forearm blood flow by plethysmography and forearm vascular resistance during intravenous infusion of $\mathrm{PGE}_{1}$ by a peripherally placed short intravenous catheter in healthy male volunteers at infusion rates of 10,50 , and 100 $\mathrm{ng} / \mathrm{kg} / \mathrm{min}$. Forearm blood flow increased and forearm vascular resistance decreased at all rates of infusion, though the change was maximal at the highest infusion rate. In these experiments no attempt was made to measure cutaneous blood flow separately from forearm blood flow and the method of administration differed from our own.

The relevance of these measurements of total forearm blood flow in healthy male volunteers to the clinical condition of Raynaud's phenomenon is questionable. Moreover, Clifford et $a l^{5}$ demonstrated increased blood flow to the hand at the rates of infusion we employed. Studies of the effect of the different prostaglandin $\mathrm{PGE}_{2}$ ( $\mathrm{Mr}$ Gaylarde's ref $^{6}$ ) on isolated human dermal arterioles are irrelevant to any discussion of the effects of $\mathrm{PGE}_{1}$ and $\mathrm{PGI}_{2}$ in vivo, while events in the skin of other species occurring during prostaglandin-induced hyperthermia, often induced by intracerebral administration of the drug, must be of highly questionable relevance to the clinical situation of Raynaud's phenomenon, in which we and others ${ }^{6}$ have employed the infusion of prostaglandin $\mathrm{E}_{1}$ and prostacyclin with therapeutic success and have been able to demonstrate changes in blood flow to the hand. ${ }^{3-7}$

The changes in erythrocyte deformability following the infusion of $\mathrm{PGI}_{2}$ in freshly prepared buffered solution and $\mathrm{PGE}_{1}$ at rates sufficient to affect hand blood flow $^{5}$ have recently been confirmed on suspensions of erythrocytes in vitro (Kovacs et al, unpublished observations). Even had the infusion rates employed resulted in no demonstrable change in haemodynamic values it does not follow that red cell deformability might not be altered, for the dissociation of pharmacological effect of different doses of a variety of drugs is well recognised. Moreover, it should be emphasised that in our study prostaglandins released at the catheter tip into the circulation would immediately come into contact with millions of erythrocytes. This is a different situation from that pertaining when prostaglandins peripherally administered have to traverse the pulmonary circulation before reaching a remote tissue in order to exert their pharmacological effect.

\section{Pauline Dowd}

St Bartholomew's Hospital,

London EC1A 7BE

Cho MG, Allen MA. Prostaglandins 1978;25:943-54 (Biol) 1981;294:305-29.

$F$, Dieppe $P$, Kirby $J$ Ann Rheum Dis 1980;39:194.

A A ${ }^{5}$ Clifford PC, Martin MFR, Sheddon, EJ, et al. B Med f 1980;281:1031.

Belch JJS, Newman P, Drury JK, et al. Thromb Haemost 1981;45:255-6.

' Dowd PM, Martin MFR, Bowcock SA, Cooke E,
Dieppe PA, Kirby JDT.Br J Dermatol (in press).

\section{The new psychiatry}

SIR,-I read your leading article "The new psychiatry" (22 August, p 513) shortly after an hour of psychotherapy supervision with a junior colleague. He had reported a patient's treatment session which followed a dexamethasone suppression test. The initial dialogue (recorded on audio tape) is pertinent.

Doctor: Well?

Patient: Well, I had that test and apparently I'm depressed ... huh ... and I'm on antidepressants. I don't like them much, but still ... hmm ... I thought I'd come to a standstill.

Doctor: So the depression has been proved.

Patient: (Sardonic laugh) ... Big deal!

The implications for the psychotherapeutic relationship of requesting an objective diagnostic test for the patient who complains of depressed mood have yet to be evaluated. Common knowledge has not caught up with this new objectivity in psychiatry. To be told how one is feeling may strike a note of absurdity more reminiscent of a popular psychiatric joke than real life. The clinician's use of the laboratory to arbitrate on reported mood states can augment despair by suggesting to the patient that even his feelings are no longer credible.

There are undoubted therapeutic benefits to be derived from the new tests. It will be in the best interests of our patients if they are applied with the empathic insights carried on from "the old psychiatry."

David RaMPLING

Hillcrest Hospital, Australia

SIR,-Non-suppression of cortisol after administration of dexamethasone has been proposed as a biochemical marker for endogenous depression. ${ }^{1}$ With notable consistency, the majority of studies have reported this abnormality in approximately $50 \%$ of patients diagnosed as having "endogenous" depression, and in relatively few cases of reactive or secondary depressions. ${ }^{2-4}$

We have studied consecutive admissions to the Royal Melbourne Hospital using the dexamethasone suppression test. Patients were diagnosed by two psychiatrists and in those with a diagnosis of depression the Newcastle scale ${ }^{5}$ was used to classify endogenous and reactive depression. Patients were given a dose of $1 \mathrm{mg}$ dexamethasone at $2300 \mathrm{~h}$. Blood samples were collected for cortisol determination at $0800 \mathrm{~h}$ and $1600 \mathrm{~h}$ the day before and after dexamethasone administration. As psychotropic drugs do not interfere with the dexamethasone suppression test, ${ }^{1}$ these patients were allowed to continue medication. No patients were receiving steroids, phenytoin sodium, or barbiturates. A total of 125 patients were studied over a 12-month period and a diagnosis of depression was made in 97 (70 endogenous, 27 reactive). Twenty-eight other patients with various chiefly psychiatric diagnoses were also studied (13 schizophrenics, three with personality disorders, two alcoholics, two with chronic pain, two agoraphobics, two with obsessive compulsive neuroses, and four normal). Non-suppression of cortisol by dexamethasone was observed in $51 \%(\mathrm{~N}=36)$ of endogenous and $4 \%(\mathrm{~N}=1)$ of reactive depressions and in $18 \%$ of other diagnoses (two cases of schizophrenia, two of obsessive compulsive neuroses, and one of agoraphobia). The cortisol levels before administration of dexamethasone were also found to differ significantly between non-suppressors and suppressors (table).

Cortisol concentrations ( $\mathrm{nmol} / \mathrm{l}$ ) before dexamethasone administration

\begin{tabular}{lcc}
\hline & $0800 \mathrm{~h}$ samples & $1600 \mathrm{~h}$ samples \\
\hline Suppressors & $516 \pm 174$ & $323 \pm 119$ \\
Non-suppressors & $770 \pm 226^{*}$ & $500 \pm 204^{*}$ \\
\hline
\end{tabular}

${ }^{*} \mathrm{p}<0.01$ (Mann-Whitney U test) Conversion: SI to traditional units-Cortisol: $1 \mathrm{nmol} \approx$
$0.036 \mathrm{\mu g} / 100 \mathrm{ml}$.

It was noted that the majority of these patients who showed non-suppression failed to respond satisfactorily to antidepressant medication, and eventually required electric convulsion therapy: 22 of 33 non-suppressors required electric convulsion therapy compared with 15 of 62 suppressors. Although the present study did not account for severity of illness, it is evident that significantly more non-suppressors required treatment by electric convulsion therapy $(p<0.05$, $\chi^{2}$ test). Similar findings have been previously reported. $^{6}{ }^{7}$ McLeod $^{6}$ found that 26 of 35 nonsuppressors needed electric convulsion therapy after antidepressant treatment for four weeks, compared with 15 of 35 suppressors. These findings may indicate some reversible abnormality of hypothalamic functioning which is associated with a depressive syndrome that responds best to electric convulsion therapy and responds poorly to antidepressants. 